\title{
Mechanisms in the haptic horizontal-vertical illusion: Evidence from sighted and blind subjects
}

\author{
MORTON A. HELLER and TAMALA D. JOYNER \\ Winston-Salem State University, Winston-Salem, North Carolina
}

\begin{abstract}
The haptic horizontal-vertical illusion was studied in two experiments. In Experiment 1, the illusion was relatively weak in sighted subjects and depended on stimulus size and the nature of the figure, that is, whether the pattern was an inverted-T or $L$ shape. Experiment 2 compared early blind and late blind subjects. The illusion was present for an inverted-T figure but absent for an L figure in late blind subjects. However, the early blind subjects treated both the $\mathrm{L}$ and T figures as similar and showed the illusion to both. These results support the idea that visual experience may alter haptic judgments in sighted and late blind subjects.
\end{abstract}

Many researchers have been interested in discovering what tactile illusions can tell us about spatial perception (Craig, 1931; Day, 1990; Day \& Avery, 1970; Fry, 1975; Over, 1967, 1968a, 1968b). The horizontal-vertical illusion has been studied extensively, and some researchers find that the vertical member of an inverted $\mathrm{T}$ is judged as longer than the horizontal member in both vision and touch (see Appelle, 1991; Over, 1968b; but see Hatwell, 1960).

The presence of illusions in both senses is important for a number of reasons. Should similar processes occur in both vision and touch, we might then assume that the senses operate in a similar fashion and provide information about the "same space." However, should differences appear, we would be justified in adopting caution in attempting to generalize what we know about vision to the tactual domain. That is why so many researchers have been interested in studying tactile illusions in blind people (see Bean, 1938; Tsal, 1967). The presence of haptic illusions in congenitally blind individuals could not be explained in terms of either visual experience or visual imagery.

Our information about haptic illusions is not clear-cut, since haptic illusions show decrements with practice (Over, 1967) and vary with orientation (Day \& Avery, 1970; Day \& Wong, 1971). Day and Wong explained the horizontal-vertical illusion in terms of radial-tangential effects, where radial movements toward or away from the body are judged as longer than other tangential movements along the front or side of the body (see Wong,

Preparation of this report and some of the research were supported by NIH MBRS Grant 2 SO6 RR-08040. Faith Heller, Christopher W. Tyler, and three anonymous reviewers provided helpful comments on earlier versions of this manuscript. We are grateful to Carl Perry for Figure 1 and to Aretha Jones and Katrina Covington for assistance with data collection and analyses. Correspondence should be addressed to M. A. Heller, Department of Psychology, Winston-Salem State University, Winston-Salem, NC 27110.
1977). Moreover, the illusion occurred visually with the L figure, but not haptically when radial motions were eliminated (Day \& Avery, 1970). Day and Avery linked the inverted-T illusion to bisection, since the divided line in the inverted $T$ was judged as shorter than the continuous vertical segment. Bisection was pitted against radial-tangential effects in a study by Tedford and Tudor (1969). They reported that the illusion was altered by orientation when a $90^{\circ}$ rotation made the continuous line segment horizontal rather than vertical. They found haptic overestimation of the continuous horizontal segment of the $90^{\circ}$-rotated-T figure, which was due to bisection effects. Tedford and Tudor further reported that orientation had a greater effect on touch than on vision. Over (1968a) found that instructions affect vision and touch differently, with touch unaffected by instructions to attend to "apparent size" rather than objective size. The experiments of Fry (1975) further clouded the issue, since the horizontal-vertical illusion was found for active touch but was reversed for passive touch. It should be pointed out that Fry provided severe temporal restrictions on exploration, and this could alter results (Heller, 1984).

It is likely that visual experience alters haptic perception in sighted subjects (Heller, 1991) and could contribute to the illusion. Revesz (1950) noted that sighted subjects tend to generate visual images when feeling patterns. Furthermore, visual imagery can influence haptic judgments of orientation (Appelle \& Countryman, 1986). Heller (1989) found evidence for the effects of visual experience on recognition of tangible displays. The late blind were far more accurate than were sighted and congenitally biind subjects in haptic recognition of raised-line drawings. In part, the advantage of the late blind was ascribed to early visual experience with line drawings. Thus, we may have limited knowledge of a "purely" haptic horizontal-vertical illusion, since most research has involved the study of blindfolded, sighted subjects. Haptic perception in late blind people may be altered by visual experience, and 
there is evidence that the late blind retain visual imagery. However, the few reported studies of the horizontal-vertical illusion in blind subjects have used either very informal methods (e.g., Bean, 1938) or mixed samples of early and late blind subjects (e.g., Hatwell, 1960). Hatwell reported attenuated illusory effects in a sample of early and late blind children. Hatwell used small (31-mm) $T$ and $L$ figures composed of embossed Braille-sized dots. She found no illusion for the $\mathrm{L}$ figure, but a relatively weak illusion in the $\mathrm{T}$ figure.

The present study attempted to clarify the mechanisms underlying the haptic horizontal-vertical illusion in sighted and blind subjects. The first experiment manipulated stimulus size with $L$ and inverted-T figures. This preliminary experiment examined the relative influence of bisection and radial-tangential effects in touch. The second experiment looked at the role of visual experience in haptics by studying the illusion in early and late blind subjects. The present set of experiments was designed to determine if similar processes could explain illusory effects in both vision and touch.

\section{EXPERIMENT 1 \\ $L$ and Inverted-T Figures}

Most studies of the tactile horizontal-vertical illusion have used large patterns (e.g., $7.5 \mathrm{~cm}$ in Day \& Avery, $1970 ; 7.5 \mathrm{~cm}$ in Day \& Wong, $1971 ; 7.5 \mathrm{~cm}$ in Deregowski \& Ellis, 1972;10-20 cm in Over, $1967 ; 15 \mathrm{~cm}$ in Tedford \& Tudor, 1969; 7.5-36 cm in Wong, 1977), and the reported results could be specific to stimulus size. This would be expected, since Over (1966) found that stimulus size altered movement extent and a resulting length illusion. It should be understood that "large" is a relative term. An extent of $7.5 \mathrm{~cm}$ is large with reference to the fingertip, but not when compared to the arm. Large movements will engage very different muscle groupings than will much smaller movements that might limit proprioceptive input to the fingers. If one manually traces a horizontal 7.5-cm standard (Day \& Wong, 1971), the wrist will move, whereas whole arm movements could be engaged with larger figures (Over, 1967). Consequently, the experiments reported here used a range of figure sizes to include smaller Ls and inverted Ts than have been used in other studies. It was thought likely that the illusion might show a decrement with smaller stimuli, well within the span of the hand, because smaller patterns presumably drive finger movements rather than whole-hand or arm movements. A group of subjects examined $\mathrm{L}$ shapes to determine if the horizontal-vertical illusory effects were a consequence of bisection, rather than radial-tangential scanning effects.

\section{Method}

Subjects. The subjects were 20 sighted subjects (12 males and 8 females) recruited from an undergraduate population. Half of the subjects were exposed to inverted-T figures (6 males and 4 females), and the rest of the subjects examined $\mathrm{L}$ figures.
Stimuli and Apparatus. The stimuli were produced with a Swedish raised-line drawing kit and a medium-point, black ballpoint pen (see Heller, 1989, in press; Heller \& Kennedy, 1990). A durable raised line was produced when the pen was pressed and drawn over the textured plastic surface. The thick, black line was both tangible and visible (see Heller, in press). The four Ls and four inverted Ts were drawn with equal vertical and horizontal segments of 2.54, $5.08,7.62$, and $10.16 \mathrm{~cm}$.

Design and Procedure. Independent groups of subjects examined standard raised-line $L$ or inverted, raised-line $T$ figures. The experiment was a mixed design, with repeated measures on horizontal versus vertical judgments and size. The subjects were tactually exposed to a random arrangement of the four standard, raised-line patterns. They were told to feel the entire pattern with the tip of the index finger of the preferred hand (as measured by writing preference). Subsequently, the subjects were told to indicate their judgments of the size of the top or bottom portions of the standard figures with the index finger and thumb in a pincers posture (see Figure 1). During size estimates, each subject held the hand roughly parallel to the table surface, palm down. A ruler was used to measure finger span. Time limits were not imposed, but the subjects were not allowed to reexamine the standard figures while making size judgments. The subjects were instructed not to make measuring (pincers) motions with the hand used to touch the figures. Half of the subjects in each group first made estimates of the tops of the figures, and the other half first made judgments of the extent of the bottoms. A Masonite baffle with a cloth-covered opening at its base was used to eliminate the subjects' sight of their hands and the models. The subjects were given no information about the nature of the stimuli, other than that they were produced with a raised-line drawing kit. Furthermore, they were given no feedback on their judgments.

\section{Results and Discussion}

A mixed-factor analysis of variance (ANOVA) showed a highly significant effect of stimulus size $[F(3,54)=153$, $p<.001]$. However, the effect of type of figure was marginal $[F(1,18)=4.1, p=.055]$. The effect of horizontal versus vertical judgments failed to reach significance $[F(1,18)=1.9, p=.18]$, and all of the interactions were

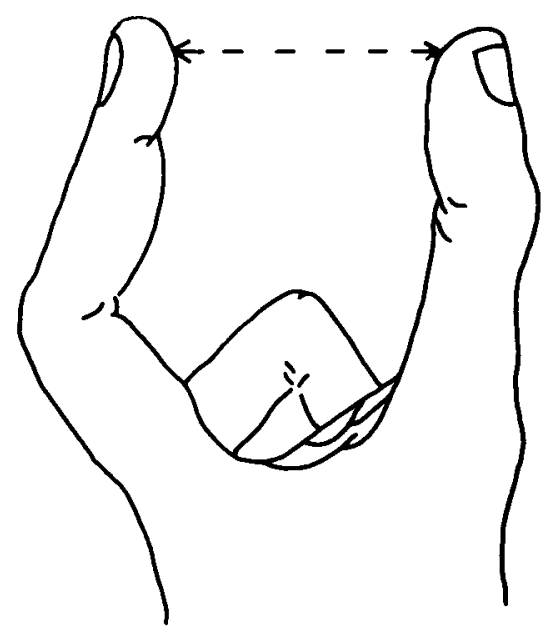

Figure 1. Finger-span method used by the subjects to estimate the dimensions of the stimuli. Measurements were taken of the span between the pads of the index finger and thumb. 
Table 1

Effect of Size on Mean Estimates (in Centimeters) of Horizontal and Vertical Segments of the Inverted-T and $L$ Figures (Experiment 1)

\begin{tabular}{|c|c|c|c|c|}
\hline \multirow{3}{*}{$\begin{array}{c}\text { Actual } \\
\text { Size }\end{array}$} & \multicolumn{4}{|c|}{ Judged Size } \\
\hline & \multicolumn{2}{|c|}{ Vertical } & \multicolumn{2}{|c|}{ Horizontal } \\
\hline & $M$ & $S D$ & $M$ & $S D$ \\
\hline \multicolumn{5}{|c|}{ Inverted-T Figure } \\
\hline 2.5 & 3.0 & 1.1 & 2.9 & 0.8 \\
\hline 5.1 & 4.8 & 2.0 & 5.2 & 1.2 \\
\hline 7.6 & 9.0 & 1.8 & 7.4 & 2.2 \\
\hline 10.2 & 10.2 & 2.0 & 9.6 & 2.0 \\
\hline Overall & 6.8 & & 6.3 & \\
\hline \multicolumn{5}{|c|}{ L Figure } \\
\hline 2.5 & 3.6 & 1.0 & 3.9 & 1.4 \\
\hline 5.1 & 6.6 & 2.1 & 6.3 & 1.7 \\
\hline 7.6 & 9.0 & 2.3 & 9.3 & 2.4 \\
\hline 10.2 & 12.1 & 2.8 & 11.5 & 2.8 \\
\hline Overall & 7.8 & & 7.7 & \\
\hline
\end{tabular}

nonsignificant. A triple interaction among type of figure, size, and horizontal versus vertical judgments failed to reach significance $[F(3,54)=2.1, p=.11]$. The expected illusion did not appear overall and was conspicuously absent for the smaller inverted-T configurations (see Table 1).

The T-condition subjects were originally tested a number of months before the $\mathrm{L}$ figure group. The combined statistical analysis seemed logical and was reported above. A separate ANOVA was initially performed on the sizeestimate data from the inverted- $T$ group alone and showed a significant effect of stimulus size $[F(3,27)=68.5$, $p<.001]$ and a significant effect of horizontal versus vertical judgments $[F(1,9)=11.4, p<.01]$, but the interaction between size and horizontal versus vertical judgments was also significant $[F(3,27)=3.3, p<.05]$. An examination of the means revealed that the illusion only appeared for larger patterns. The difference between the means for the horizontal and vertical segments of the $7.62-\mathrm{cm}$ standard inverted $\mathrm{T}$ was significant, but all of the other comparisons failed to reach significance (all $p s>.05$ ). Thus, there was no illusion for the smaller patterns. A separate analysis on data from the L-figure group showed that no illusion appeared in the $\mathrm{L}$ figure and the only significant effect was for stimulus size $\left[F(3,27)=86.1, p<.001\right.$, all other $\left.F_{\mathrm{s}}<1\right]$.

The results of the present experiment are consistent with prior studies that ascribe the horizontal-vertical illusion, when it appears, to bisection. ${ }^{1}$ However, the failure to find the illusion for small patterns $(<5 \mathrm{~cm})$, even with the inverted $\mathrm{T}$, suggests an additional explanation. It might also be possible to think of the horizontal-vertical illusion as an illusion of proprioception (and radial-tangential movement effects), rather than "touch" or "haptics" per se. Thus, larger patterns maximize the role of proprioceptive input from arm movements. In smaller configurations, however, cutaneous input plays a larger role and movement can be accomplished with the fingers alone.
Further research will be needed to determine if illusory effects are general phenomena in haptics or if they are linked to circumstances involving the movement of the arms combined with bisection effects. The marginal effect of figure, along with the nonsignificant overall effect of horizontal versus vertical judgments, is consistent with this interpretation.

The $\mathrm{L}$ figure produced consistent overestimation of both horizontal and vertical lines. The data show an "overestimation illusion" that cannot be attributed simply to radial-tangential effects. There was no evidence for radial-tangential effects with the $\mathrm{L}$ figure. Although the effect was weak, there was an apparent alteration in perceived length in the inverted $T$ due to the effect of bisection, with bisection further reducing perceived overall size. It is also possible, however, that the presence of the illusion depends on the combined effects of bisection, radial motion, and visual status. Thus, it is conceivable that sighted subjects visualize the patterns and that this visualization alters their judgments (see Revesz, 1950). The next experiment examined this possibility.

\section{EXPERIMENT 2 Effect of Visual Experience}

The purpose of the second experiment was to examine the influence of visual experience on the tactile horizontalvertical illusion. The present research attempted to determine if the early and late blind differ in their perception of $\mathrm{T}$ and $\mathrm{L}$ figures. The late blind may generate visual images, and this tendency to visualize could influence haptic judgments. It is also possible that their history of visual experience, including exposure to pictures, could alter their perception of raised-line configurations (see Heller, 1989; Heller \& Kennedy, 1990).

\section{Method}

Subjects. The subjects were 9 early blind and 9 late blind volunteers recruited at Industries of the Blind workshops in WinstonSalem and Greensboro and in the community of Winston-Salem. None of the subjects with light perception could see form or hand movements. All of the early blind subjects were blind at birth (or when removed from incubators, in the case of the retrolental fibroplasia subjects), with the exception of 2 subjects who lost sight at 3 and 10 months, respectively. Table 2 shows the characteristics of the blind subjects.

Stimuli and Apparatus. The stimuli were $\mathrm{L}$ and inverted- $\mathrm{T}$ raised-line figures, in the same sizes as studied in Experiment 1.

Design and Procedure. The experiment was a mixed design, with visual status (early vs. late blind) as the between-group variable and with repeated measures on figure ( $T$ or $L$ ) and size. The subjects alternated initial exposure to the $\mathrm{T}$ or $\mathrm{L}$ figures. Additionally, about half of the subjects used the left index finger to examine the figure and the right hand for size judgments; the rest of the subjects reversed the hands for haptic examination and size estimation. In other respects, the procedure was similar to that of the first experiment.

\section{Results and Discussion}

The results are shown in Table 3 and reveal a complex relationship between visual status, the presence of the illusion, figure, and size. A mixed-factor ANOVA on size 
estimates indicated highly significant effects of size $[F(3,48)=577.1, p<.001]$ and vertical versus horizontal estimates of extent $[F(1,16)=35.9, p<.02]$. None of the other main effects approached significance (all $F$ s $<1$ ). Visual status, however, did show significant triple interactions with the horizontal versus vertical judgments and size $[F(3,48)=3.9, p<.02]$ and with the nature of the figure $[F(1,16)=13.7, p<.05]$. None of the other interactions was significant. The interaction effects suggest that the late blind subjects responded more like the sighted subjects in the earlier experiment, since they did not show an illusion with the $\mathrm{L}$ figure. Thus, they treated the two figures differently, and the illusion was only obvious for the inverted-T shapes. The early blind subjects treated the $T$ and L figures alike, especially the largest and smallest, with no illusion at all in the 2.54-cm patterns. It was interesting that the illusion seemed robust in the $\mathrm{L}$ pattern for the early blind subjects.

Visual experience altered the pattern of judgments in the present experiment, although in a rather complex manner. Subject variables clearly magnified both the effects of figure and the illusion. This suggests that haptic processing of tangible patterns may differ depending on either visual imagery or past exposure to line drawings. The early blind subjects did not seem influenced by line bisection, since they showed the strongest illusory effects with the $L$ patterns. The presence of the illusion in the $L$ figure, together with the absence of the illusion for the smallest patterns, implicates the possible role of radialtangential effects in haptic judgments. Hatwell found a bisection effect in the horizontal-vertical illusion with

Table 2

Characteristics of the Blind Subjects, Including Gender, Age, Presence of Light Perception, Cause of Blindness, and Education

\begin{tabular}{cclll}
\hline Gender & Age & LP & \multicolumn{1}{c}{ Cause } & Education \\
\hline & & & Early Blind & \\
F & 25 & No & Optic nerve & SC \\
M & 28 & Yes & Optic nerve & HS \\
M & 35 & Yes & RLF & SC \\
$F$ & 36 & No & RLF & SC \\
$F$ & 39 & Yes & RLF & HS \\
$F$ & 52 & No & Born without eyes & HS \\
M & 53 & No & Glaucoma & HS \\
$F$ & 54 & No & Infection & HS \\
$F$ & 54 & Yes & RP, congenital nystagmus & HS \\
& & & and kerataconus & \\
& & & & \\
& & & Late Blind & \\
$M$ & 26 & No & Detached retinas & HS \\
M & 26 & No & Glaucoma & SC \\
$F$ & 26 & No & RLF & SC \\
$M$ & 28 & No & Trauma & Some HS \\
$F$ & 35 & Yes & RP & HS \\
$M$ & 38 & No & RP & SC \\
$M$ & 43 & No & Detached retinas & SC \\
$M$ & 44 & No & Glaucoma & HS \\
$M$ & 54 & No & Trauma & SC \\
\hline
\end{tabular}

Note-Many blind subjects attended rehabilitation programs after finishing high school. $\mathrm{LP}=$ light perception, $\mathrm{RP}=$ retinitis pigmentosa, $\mathrm{RLF}=$ retrolental fibroplasia, $\mathrm{HS}=$ high school, $\mathrm{SC}=$ some college .
Table 3

Effect of Size on Mean Estimates (in Centimeters) of Horizontal and Vertical Segments of the Inverted-T and $L$ Figures for Late-Blind (LB) and Congenitally Blind (CB) Subjects

\begin{tabular}{|c|c|c|c|c|c|}
\hline \multirow{3}{*}{$\begin{array}{c}\text { Actual } \\
\text { Size }\end{array}$} & \multirow[b]{3}{*}{ Subjects } & \multicolumn{4}{|c|}{ Judged Size } \\
\hline & & \multicolumn{2}{|c|}{ Vertical } & \multicolumn{2}{|c|}{ Horizontal } \\
\hline & & $M$ & $S D$ & $M$ & $S D$ \\
\hline \multicolumn{6}{|c|}{ Inverted-T Figure } \\
\hline $\begin{array}{r}2.5 \\
5.1 \\
7.6 \\
10.2\end{array}$ & $\mathrm{CB}$ & $\begin{array}{r}4.3 \\
7.1 \\
10.2 \\
11.8\end{array}$ & $\begin{array}{l}2.2 \\
2.3 \\
2.8 \\
2.7\end{array}$ & $\begin{array}{l}4.3 \\
6.6 \\
9.6 \\
9.9\end{array}$ & $\begin{array}{l}2.3 \\
1.8 \\
2.9 \\
2.7\end{array}$ \\
\hline $\begin{array}{r}2.5 \\
5.1 \\
7.6 \\
10.2\end{array}$ & LB & $\begin{array}{r}4.6 \\
7.1 \\
9.6 \\
10.7\end{array}$ & $\begin{array}{l}2.3 \\
2.4 \\
2.0 \\
2.4\end{array}$ & $\begin{array}{l}3.4 \\
6.4 \\
7.9 \\
9.6\end{array}$ & $\begin{array}{l}1.9 \\
2.2 \\
2.3 \\
2.1\end{array}$ \\
\hline \multicolumn{6}{|c|}{ L Figure } \\
\hline $\begin{array}{r}2.5 \\
5.1 \\
7.6 \\
10.2\end{array}$ & CB & $\begin{array}{r}3.8 \\
7.7 \\
9.9 \\
11.4\end{array}$ & $\begin{array}{l}1.4 \\
2.2 \\
2.3 \\
2.6\end{array}$ & $\begin{array}{l}3.8 \\
6.7 \\
8.4 \\
9.4\end{array}$ & $\begin{array}{l}1.6 \\
1.4 \\
3.3 \\
2.7\end{array}$ \\
\hline $\begin{array}{r}2.5 \\
5.1 \\
7.6 \\
10.2\end{array}$ & LB & $\begin{array}{r}4.6 \\
6.9 \\
9.0 \\
11.0\end{array}$ & $\begin{array}{l}0.9 \\
1.3 \\
2.4 \\
2.8\end{array}$ & $\begin{array}{r}4.6 \\
7.1 \\
9.1 \\
11.4\end{array}$ & $\begin{array}{l}0.9 \\
1.7 \\
2.6 \\
2.4\end{array}$ \\
\hline
\end{tabular}

blind subjects, but used a mixed group of early and late blind individuals ranging in age from 8 to 17 (Hatwell, $1960 ; 1986$, p. 207). Although not a parsimonious explanation, it is always possible that the illusion in the early blind depends on bisection in the inverted-T figure and radial-tangential effects in the $L$ figure.

The late blind showed no evidence of the illusion in the $\mathrm{L}$ pattern, indicating that their illusory responses were affected by bisection, as were the sighted subjects' in the earlier experiment. This effect of visual experience requires further comment, since it might be tempting to ascribe the effect to the generation of visual images during haptic exploration. However, although the late blind subjects had been exposed to line drawings (prior to the onset of blindness), we should recognize that the early blind subjects had minimal exposure to raised-line drawings. It is very possible that this relative lack of familiarity with two-dimensional configurations (in the form of line drawings) could have altered their judgments in the direction noted. Thus, it is difficult to tell if the different pattern of responding derives from something intrinsic to haptic coding or from minimal practice with T-like, twodimensional patterns. Practice has been shown to have a robust effect on kinesthetic judgments, as revealed by drawing (Laszlo \& Bairstow, 1983). It is impossible, of course, to rule out the visual imagery interpretation.

\section{GENERAL DISCUSSION}

The experiments indicate that the horizontal-vertical illusion occurs in touch, but the magnitude of the illusion depends on visual experience and stimulus size. In the first 
experiment, with sighted subjects, a different pattern of responses was obtained for an inverted-T figure and for an $L$ shape. The illusion failed to appear overall for sighted subjects; illusory effects were weak and were linked to the 7.6-cm inverted-T figure. Moreover, the illusion also depended on stimulus size and was absent for smaller $T$ figures. This may reflect the diminished influence of radial-tangential effects as movement extent is reduced. The results of the second experiment with blind subjects revealed that visual experience altered performance in the interpretation of raised-line configuration. The early blind subjects treated the inverted- $\mathrm{T}$ and $\mathrm{L}$ figures as alike and showed the illusion for larger patterns, whereas the late blind evidenced an illusion with the inverted-T figure but showed no illusion with the L figure. Thus, the early blind subjects did not respond to line bisection in the same way as did the late blind subjects in these experiments. Line bisection should reduce estimates of the horizontal relative to the vertical for lines of equal length (see Coren \& Girgus, 1978).

The effect of visual status in the second experiment suggests caution in generalizing about haptics from the results of studies of blindfolded, sighted subjects using touch. The sighted subjects showed a marginal effect of figure, the late blind subjects were especially sensitive to bisection, and the early blind subjects showed evidence of radial-tangential scanning effects. The illusion may occur in both vision and touch, but for different reasons. Vision may be influenced by the shape of the visual field (Künnapas, 1955), bisection and depth cues (Girgus \& Coren, 1975), or retinal meridians (Avery \& Day, 1969). The illusion still occurs in a weaker form in vision when the L figure is used (Coren \& Girgus, 1978). Touch may show the illusion in haptic conditions with sighted subjects because of prior visual exposure to $T$ junctions, both two dimensional and three dimensional. Thus, any illusory effects were a joint effect of haptics and a history of vision in the late blind and sighted subjects. The early blind subjects did not respond differently to the inverted$T$ and $L$ figures, but showed the illusion to both. Moreover, the nonsignificant effect of figure for early blind subjects in Experiment 2 suggests that the early blind subjects were not responding to bisection. Further research will be needed to test the generality of these findings.

It is also possible to interpret the presence of the illusion in the early blind as an indication of a basic similarity between haptic and visual processing. It should be noted that the following ideas are speculative. Visual judgments of extent may depend on comparisons of the size of a line with respect to the size of the visual field. The visual field has been described as larger in the horizontal than the vertical dimension, and field shape is relevant to the horizontal-vertical illusion. This assumes that the vertical line takes up a larger portion of the vertical visual field than an equivalent horizontal line and is then perceived as longer. It is also possible to describe the haptic field as oval, in a similar way, since one's horizontal space (between laterally outstretched hands, shoulder height; frontoparallel plane) is larger than one's frontal (or vertical) space. One's frontal, manipulatory space is limited to the length of one arm extended forward while a person is seated at a desk or table (see Merleau-Ponty, $1942 / 1967$, pp. 215,249 ). Thus, the phenomenal experience of haptic space may vary depending on whether a person is seated or standing and on whether the person is in an open field, a large space, or a small room. Phenomenal haptic space may be compressed and limited to "in front" and to "the sides" when one stands or sits with his/her back to a wall. Even while standing, frontal haptic space could be larger than the space to one's rear because of reduced flexibility of the arms in reaching backward. Note that the orientation and width of the body contribute to horizontal manipulatory space. People may compare a vertical line in haptics to a compressed vertical space and then overestimate lines that are compared with a larger, horizontal space.

According to this interpretation of the data, the early blind respond to a phenomenal, manipulatory haptic space that is vertically compressed, much like visual space. The early blind subjects' failure to respond to bisection could simply derive from inexperience with raised-line configurations. The late blind also lack experience with raisedline drawings, but they may have been more sensitive to bisection because of a history of visual exposure to line drawings. Additional research will be required to clarify the nature of haptic space in the early blind.

The report by Day and Avery (1970) appears inconsistent with this notion of a common space, since the illusory effect in the $\mathrm{L}$ figure vanished when radial-tangential motions were controlled for (see also Deregowski \& Ellis, 1972). They were able to eliminate radial scanning motions by orienting the $T$ and $L$ figures vertically, as on a CRT screen. However, it is not clear why the illusion did not appear in sighted subjects in haptic conditions in the 7.6-cm L figure in Experiment 1, as vertical motions were radial. Perhaps bisection is a more potent cue for sighted subjects limited to haptics (see Note 1).

Furthermore, it is likely that radial-tangential scanning effects are stronger and more common with arm movements and larger stimuli. One reviewer pointed out that radial movements are executed more slowly than are tangential motions and are judged as longer (see Wong, 1977). This suggests that the haptic horizontal-vertical effect is influenced by the time taken to execute movements. Apparent extent is determined by the speed with which subjects scan stimuli. Thus, there is a "space-time" basis of the effect, especially with larger motions and patterns ranging in size from 7.5 to $36 \mathrm{~cm}$. Wong used an apparatus that controlled exploration and apparently forced arm movements, since the $L$ figure in his Experiments 3 and 4 was $36 \mathrm{~cm}$ long. Deregowski and Ellis (1972) also required the use of arm movements, since their subjects used their middle fingers to scan stimuli. According to this alternative interpretation of the data, it is possible that the early and late blind differ in the speed with which they scan stimuli. Future research might be directed 
toward this possibility. However, differences in scanning speed alone between the early and late blind cannot explain their differential response to line bisection.

It should be noted that the present study allowed movement of the index finger, rather than arm motions for smaller stimuli. It is probable that the use of larger stimuli is an important procedural variable, since different sorts of movements are induced with large configurations. For example, lateral, horizontal motions of the index finger are more limited than are forward, vertical-radial motions when the palm faces down. A 7.6-cm horizontal line may prompt movement of the finger and hand (or arm). The present results are consistent with Hatwell's (1960) report of attenuated illusory effects with small T figures and no illusion with $L$ figures.

Also, it should be noted that most studies of haptic illusions have used blindfolded sighted subjects, whereas a barrier was used to control vision for sighted subjects in the first experiment. It is not known how this procedural change might have influenced the illusion.

There is a further point that should be considered. The distortion induced by radial-tangential scanning effects disappeared in the L figures for the late blind subjects. These subjects had the benefit of the influence of both vision and touch. Visual experience provided a modulating effect on haptic perception in the late blind and sighted subjects, perhaps through visualization or early experience with line drawings. Thus, having a history of input from more than one modality may lead to increased accuracy in perception. This occurs via reduction in the sorts of perceptual errors that characterize illusions. ${ }^{2}$ This explanation is also consistent with the reduced illusory effects in sighted subjects in the first experiment.

The results of the present experiments have some bearing on the design of tangible displays for use by blind people. ${ }^{3}$ Bisection appears less likely to alter perceived extent in early blind subjects, and $\mathrm{T}$ junctions may be less perceptually salient for haptics. It is not known how much of this effect is due to the nature of haptics or is a result of the early blind person's relative inexperience with line drawings. It should be noted that the reported experiments do not suggest any generalized defect in perception in the blind or in haptic perception of two-dimensional line drawings. Of course, it is possible that sighted and late blind subjects respond to depth cues when haptically confronted with inverted $\mathrm{T}$ shapes and the early blind do not (see Girgus \& Coren, 1975). This possibility is a subject for future research.

\section{REFERENCES}

APPELle, S. (1991). Haptic perception of form: Activity and stimulus attributes. In M. A. Heller \& W. Schiff (Eds.), The psychology of touch (pp. 169-188). Hillsdale, NJ: Erlbaum.

Appelle, S., \& Countryman, M. (1986). Eliminating the haptic oblique effect: Influence of scanning incongruity and prior knowledge of the standards. Perception, 15, 325-329.

AVERY, G. C., \& DAY, R. H. (1969). Basis of the horizontal-vertical illusion. Journal of Experimental Psychology, 81, 376-380.

BEAN, C. H. (1938). The blind have "optical illusions." Journal of Experimental Psychology, 22, 283-289.
Coren, S., \& Girgus, J. S. (1978). Seeing is deceiving: The psychology of visual illusions. Hillsdale, NJ: Erlbaum.

Craig, F. E. (1931). Variations in the illusion of filled and unfilled tactual space. American Journal of Psychology, 43, 112-114.

DAY, R. H. (1990). The Bourdon illusion in haptic space. Perception \& Psychophysics, 47, 400-404.

DAY, R. H., \& AVERY, G. C. (1970). Absence of the horizontal-vertical illusion in haptic space. Journal of Experimental Psychology, 83, 172-173.

DAY, R. H., \& WONG, T. S. (1971). Radial and tangential movement directions as determinants of the haptic illusion in an L figure. Journal of Experimental Psychology, 87, 19-22.

Deregowski, J., \& Ellis, H. D. (1972). Effect of stimulus orientation upon haptic perception of the horizontal-vertical illusion. Journal of Experimental Psychology, 95, 14-19.

FRY, C. L. (1975). Tactual illusions. Perceptual \& Motor Skills, 40, 955-960.

Girgus, J. S., \& Coren, S. (1975). Depth cues and constancy scaling in the horizontal-vertical illusion: The bisection error. Canadian Journal of Psychology, 29, 59-65.

HatWELL, Y. (1960). Étude de quelques illusions geometriques tactiles chez les aveugles. L'Annee Psychologique, 60, 11-27.

Hatwell, Y. (1986). Toucher LEspace. France: Presses Universitaires De Lille.

HeLler, M. A. (1984). Active and passive touch: The influence of exploration time on form recognition. Journal of General Psychology, 110, 243-249.

Heller, M. A. (1989). Picture and pattern perception in the sighted and blind: The advantage of the late blind. Perception, 18, 379-389.

Heller, M. A. (1991). Haptic perception in blind people. In M. A. Heller \& W. Schiff (Eds.), The psychology of touch (pp. 239-261). Hillsdale, NJ: Erlbaum.

HELler, M. A. (in press). "Haptic dominance" in form perception: Vision versus proprioception. Perception.

Heller, M. A., \& Kennedy, J. F. (1990). Perspective taking, pictures, and the blind. Perception \& Psychophysics, 48, 459-466.

KÜNnAPAS, T. M. (1955). An analysis of the "vertical-horizontal illusion." Journal of Experiment Psychology, 49, 134-140.

Laszlo, J. I., \& Bairstow, P. J. (1983). Kinaesthesis: Its measurement, training and relationship to motor control. Quarterly Journal of Experimental Psychology, 35, 411-421.

Merleau-Ponty, M. (1967). The structure of behavior (A. L. Fisher, Trans.). Boston: Beacon. (Original work published 1942)

OVER, R. (1966). Context and movement as factors influencing haptic illusions. Australian Journal of Psychology, 18, 262-265.

OVER, R. (1967). Intermanual transfer of practice decrements with a haptic illusion. Quarterly Journal of Experimental Psychology, 19, 215-218.

OVER, R. (1968a). The effect of instructions on visual and haptic judgment of the Müller-Lyer illusion. Australian Journal of Psychology, 20, 161-164.

Over, R. (1968b). Explanations of geometrical illusions. Psychological Bulletin, 70, 545-562.

Revesz, G. (1950). The psychology and art of the blind. London: Longmans Green.

Tedford, W. H., JR., \& Tudor, L. L. (1969). Tactual and visual illusions in the T-shaped figure. Journal of Experimental Psychology, 81, 199-201.

TsaI, L. S. (1967). Mueller-Lyer illusion by the blind. Perceptual \& Motor Skills, 25, 641-644.

WARREN, D. H. (1984). Blindness and early childhood development. New York: American Foundation for the Blind.

WoNG, T. S. (1977). Dynamic properties of radial and tangential movements as determinants of the haptic horizontal-vertical illusion with an L-figure. Journal of Experimental Psychology: Human Perception \& Performance, 3, 151-164.

\section{NOTES}

1. Sighted subjects clearly show bisection effects in both vision (Girgus $\&$ Coren, 1975) and touch. An additional group of 10 subjects ( 3 males and 7 females) replicated the haptic inverted-T condition of the first ex- 
periment, but with the T rotated $-90^{\circ}$ from normal upright. This made the bisected line vertical, and the horizontal line was continuous. The orientation manipulation pitted the reducing effects of bisection against magnification induced by radial-tangential scanning effects. A repeated measures ANOVA showed a significant effect of size $[F(3,27)=93.5$, $p<.001]$ and an effect of horizontal versus vertical judgments $[F(1,9)=4.99, p=.05]$, but the interaction failed to reach significance $[F(3,27)=1.2, p>.05]$. Although the subjects generally overestimated extents, they tended to underestimate the vertical (overall $M=$ $7.18 \mathrm{~cm}$ ) relative to the horizontal, continuous line (overall $M=$ $7.56 \mathrm{~cm}$ ), a result that is similar to visual data on the effects of bisection. Overestimation of the horizontal relative to the vertical was greatest with the 2.54-cm rotated $\mathrm{T}$, a finding consistent with the diminished evidence of radial-tangential effects for smaller stimuli in the earlier experiments.

2. An anonymous reviewer noted that the early blind subjects must rely entirely on proprioceptive cues to make their size estimates. It was pointed out that the sighted and late blind subjects have learned to interpret proprioceptive signals with visual feedback. Alternatively, the sighted and late blind subjects may have also learned to interpret visual size cues in terms of proprioception and cutaneous information. In any event, a significant triple interaction was found among visual status, horizontal versus vertical judgments, and size in the second experiment. Visual status also interacted with the illusion and type of figure. This further supports the idea that visual experience alters perception of extent in tangible raised-line configurations.

3. Many researchers have directly compared sighted and blind subjects in a single experimental design, including past research by the present author (see Heller, 1991). It should be noted that there are a number of methodological reasons for not always making this sort of explicit experimental comparison (Warren, 1984).

(Manuscript received March 25, 1992; revision accepted for publication September 28, 1992.)

Forthcoming Articles (continued from page 42I)

"The representational framework in perceptual theory" by W. Epstein (W.J. Brogden Psychology Bldg., Univ. of Wisconsin, Madison, WI 53706)

"Orientation asymmetry in the flanker task" by A. Cohen \& R.E. Shoup (A.C., Dept. of Psychology, Hebrew Univ., Jerusalem, Israel)

" The effects of background visual roll stimulation on postural and manual control and self-motion perception" by F.H. Previc, R.V. Kenyon, E.R. Boer, \& B.H. Johnson (F.H.P., Crew Technology Division, Armstrong Laboratory, Brooks AFB, TX 78235-5000)

"Revisitation of the luminance conditions for the occurrence of the achromatic neon color spreading illusion"' by P. Bressan (Dipartimento di Psicologia Generale, Univ. di Padova, Piazza Capitaniato 3, Padova, 35139, Italy)

"A re-examination of duplex perception evoked by intensity differences"' by P.J. Bailey \& P. Herrmann (P.J.B., Dept. of Psychology, Univ. of York, York YO1 5DD, U.K.)

"Perception of local shape from shading" by R.G.F. Erens, A.M.L. Kappers, \& J.J. Koenderink (R.G.F.E., Univ. of Utrecht, Princetonplein 5, Utrecht 3584 CC, The Netherlands)

"Localization of electrocutaneous stimuli at the fingers and forearm: Effects of electrode configuration and body axis" by A. Higashiyama \& M. Hayashi (Psychology Lab., College of Integrated Arts \& Sciences, Univ, of Osaka Prefecture, Sakai 593, Japan)

"Interocular suppression in normal and amblyopic subjects: The effect of unilateral attenuation with neutral density filters" by R. Sireteanu \& U. Leonards (R.S., Max Planck-Inst. für Hirnforschung, Deutschordenstr. 46, D-6000 Frankfurt 71 , Germany)

"When acoustic sequences are not perceptual sequences: The global perception of auditory patterns' by R.M. Warren \& J.A. Bashford (R.M.W., Dept. of Psychology, Univ. of Wisconsin, Milwaukee, WI 53201)

"The gap between rod and frame influences the rod and frame effect with small and large inducing displays"' by P. Zoccolotti, G. Antonucci, \& D. Spinelli (P.Z., Dipartimento di Psicologia, Via dei Marsi 78, 00185 Roma, Italy)

"Properties of spatial representations: Data from sighted and blind subjects" by R.N. Haber, L.R. Haber, C.A. Levin, \& R. Hollyfield (R.N.H., Dept. of Psychology m/c 285, Univ. of Illinois at Chicago, Chicago, IL 60680)
"The normal distribution in scaling subjective stimulus differences: Less 'normal' than we think?', by A. Hellstrom (Dept. of Psychology, Stockholm Univ., S-106 91 Stockholm, Sweden)

"Concurrent processes: The affect-cognition relationship within the context of the 'mere exposure' phenomenon'" by M.A. Lee, J.L. Sundberg, \& I.H. Bernstein (I.H.B., Dept. of Psychology, Univ, of Texas at Arlington, P.O. Box 19528, Arlington, TX 76019-0528)

"Covert effects of alcohol revealed by event-related potentials" by W. Sommer, H. Leuthold, \& M. Hermanutz (W.S., Fachgruppe Psychologie, Univ. Konstanz, Postfach 5560, D-7750 Konstanz, Germany)

"Tensorial basis to the constancy of perceived object extent over variations of dynamic touch" by C.C. Pagano, P. Fitzpatrick, \& M.T. Turvey (C.C.P., Univ. of Connecticut, Ctr. for Ecol. Study of Perception \& Action, 406 Babbidge Road, U-20, Storrs, CT 06269-1020)

"Realism of confidence in sensory discrimination: The underconfidence phenomenon'" by M. Bjorkman, P. Juslin, \& A. Winman (M.B., Uppsala Univ., Dept. of Psychology, Box 1854, S-751 48 Uppsala, Sweden)

"Recovery of 3-D shape from binocular disparity and structure from motion' by J.S. Tittle \& M.L. Braunstein (J.S.T., Dept. of Psychology, Ohio State Univ., 140D Lazenby Hall, 1827 Neil Ave., Columbus, OH 43210)

"Haptic identification of objects and their depictions" by R.L. Klatzky, J.M. Loomis, S.J. Lederman, H. Wake, \& N. Fujita (R.L.K., Dept. of Psychology, Univ. of California, Santa Barbara, CA 93106-9660)

" Counterexample to the hypothesis of functional similarity between tactile and visual pattern perception" by J.M. Loomis (Dept. of Psychology, Univ. of California, Santa Barbara, CA 93106-9660)

"Additivity of loudness across critical bands: A critical test" by R. Hubner \& W. Ellermeier (R.H., Psychologisches Inst., Technische Univ. Braunschweig, Gausstrasse 23, D-3000 Braunschweig, Germany)

"Response selection, sensitivity, and taste-test performance" by J.A. Stillman (Dept. of Psychology, Massey Univ. Albany, Private Bag 102-904, N. Shore MSC, Auckland, New Zealand)

"Alternating prism exposure causes dual adaptation and gen- 